\title{
REMARKS ON THE PATHOLOGY OF SENILE HYPERTROPHY OF THE PROSTATE.
}

\author{
By R. F. TOBIN, F.R.C.S.;
}

Surgeon, St. Vincent's Hospital, Dublin.

[Read in the Section of Pathology, February 19, 1904.]

ON the anatomy and pathology of senile hypertrophy of the prostate a flood of light has, it seems to me, been thrown by a paper of Mr. Wallace's, which appeared in the British Medical Journal of 30th January, 1904. In it he shows in a satisfactory manner why, although owing to its anatomical relations it is not possible to enucleate the normal prostate, it is quite easy so to treat what is called the hypertrophied prostates of old men.

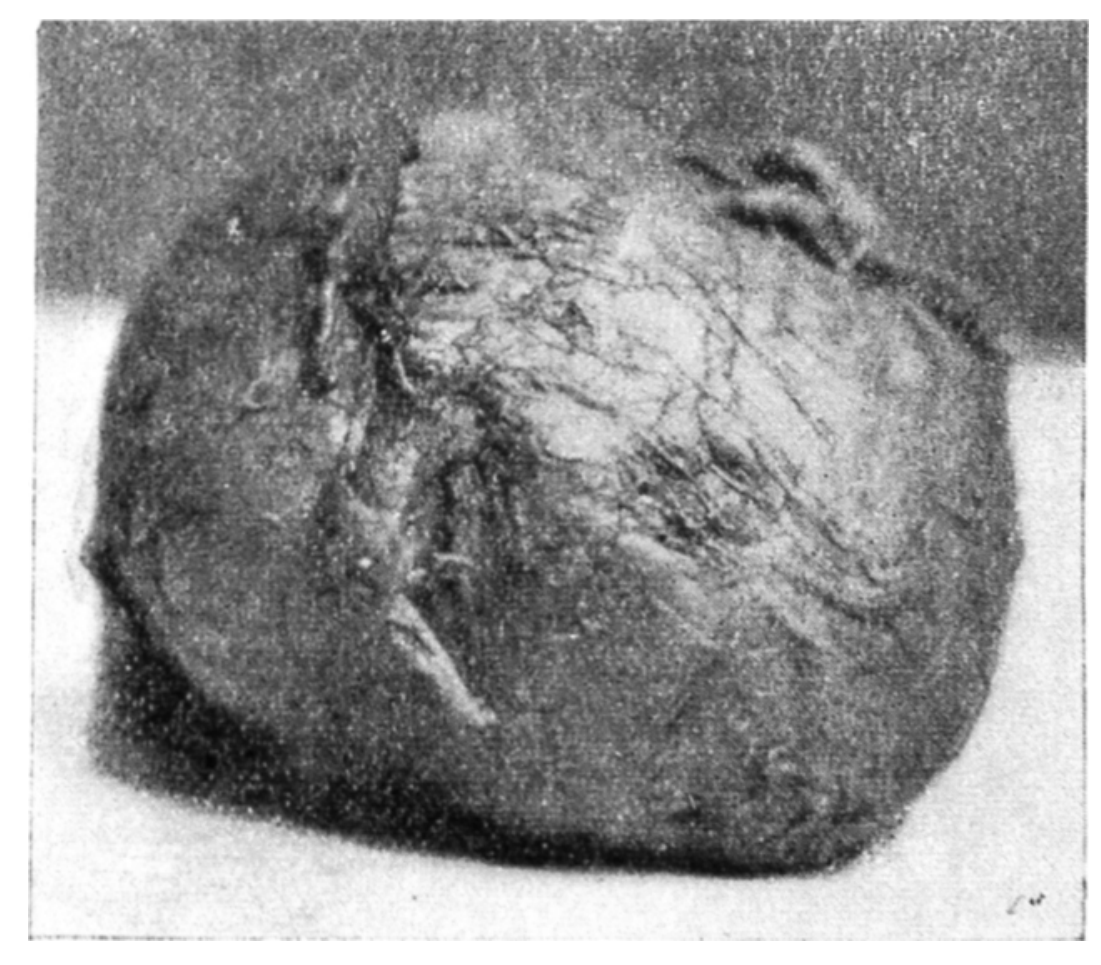

Specimen No. 1.

This is due to the fact that in such case there occurs a development of adenoid growths in the gland which tend to coalesce and to form for themselves an envelope out of the remaining structures; in other words, what has to be 
dealt with is an adenoid mass or masses lying in a laminated cover made out of the prostate. To this cover Mr. Wallace has given the name of the "surgical capsule," and he demonstrates that the operation known as enucleation of a hypertrophied prostate consists after the opening of the bladder in making a way for one's finger through the sheath-i.e., the investment derived from the recto-vesical fascia, and containing the prostatic plexus of veins, next through one or more layers of the surgical eapsule, and then shelling out the remaining unopened layers of said capsule and the adenoid growths contained therein.

Happening to have by me, when reading Mr. Wallace's paper, some recently enucleated prostates, I was able to verify for myself his remarks; and as these specimens, in addition to so doing, present some other points of interest, I beg leave to briefly call your attention to them.

Specimen No. 1 is a mass which $I$ enucleated with great ease through the superficial layers of its surgical capsule.

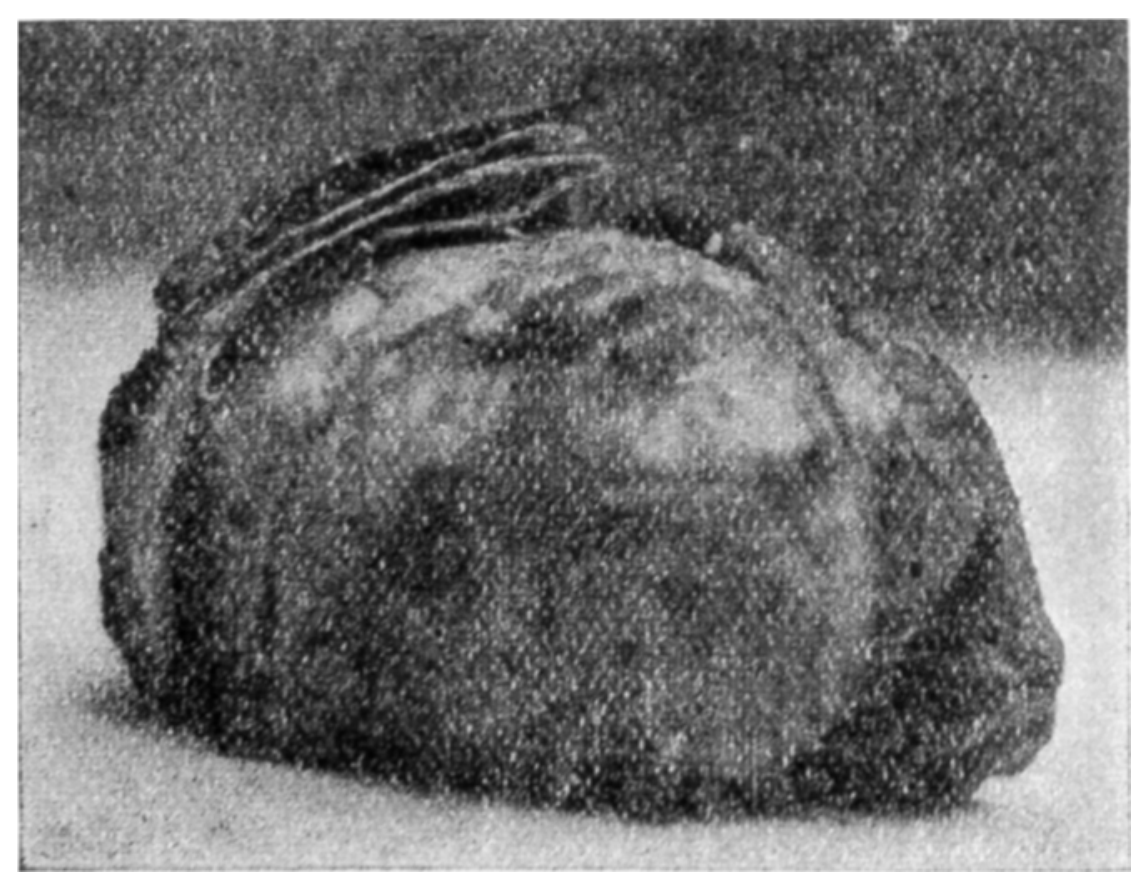

Specimen No. 2.

Specimen No. 2 is the same mass with the capsule raised and showing the layers into which it is divisible. 
Specimen No. 3 shows this layer of capsule thrown back, and embedded in it can be seen adenoid growths which, of course, would have been left behind had the enucleation been conducted at this depth.

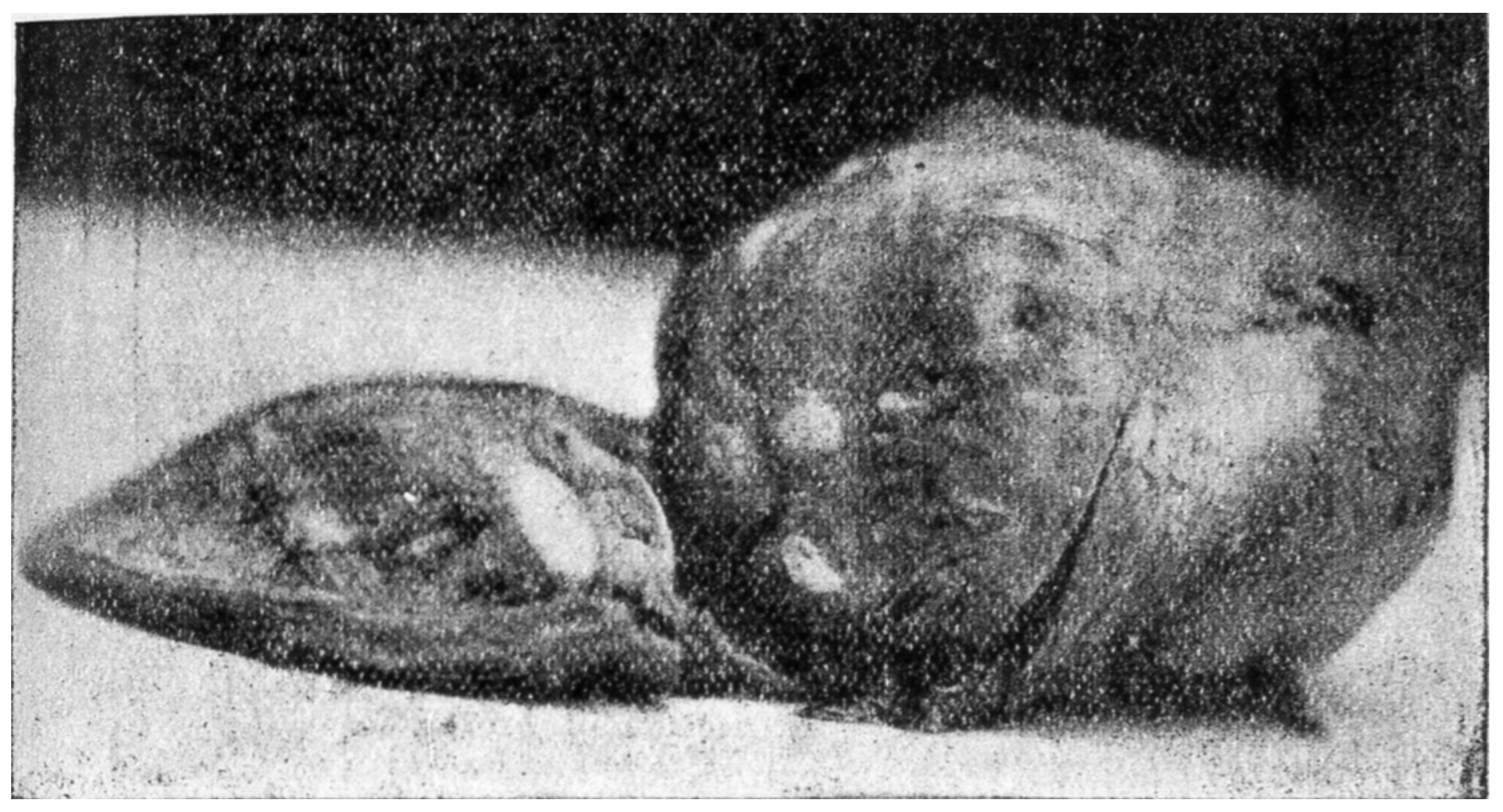

Specimen No. 3.

Specimen No. 4 shows a number of calculi which the finger came on, all at one spot, when $I$ was operating on the case we are considering. You see that they are

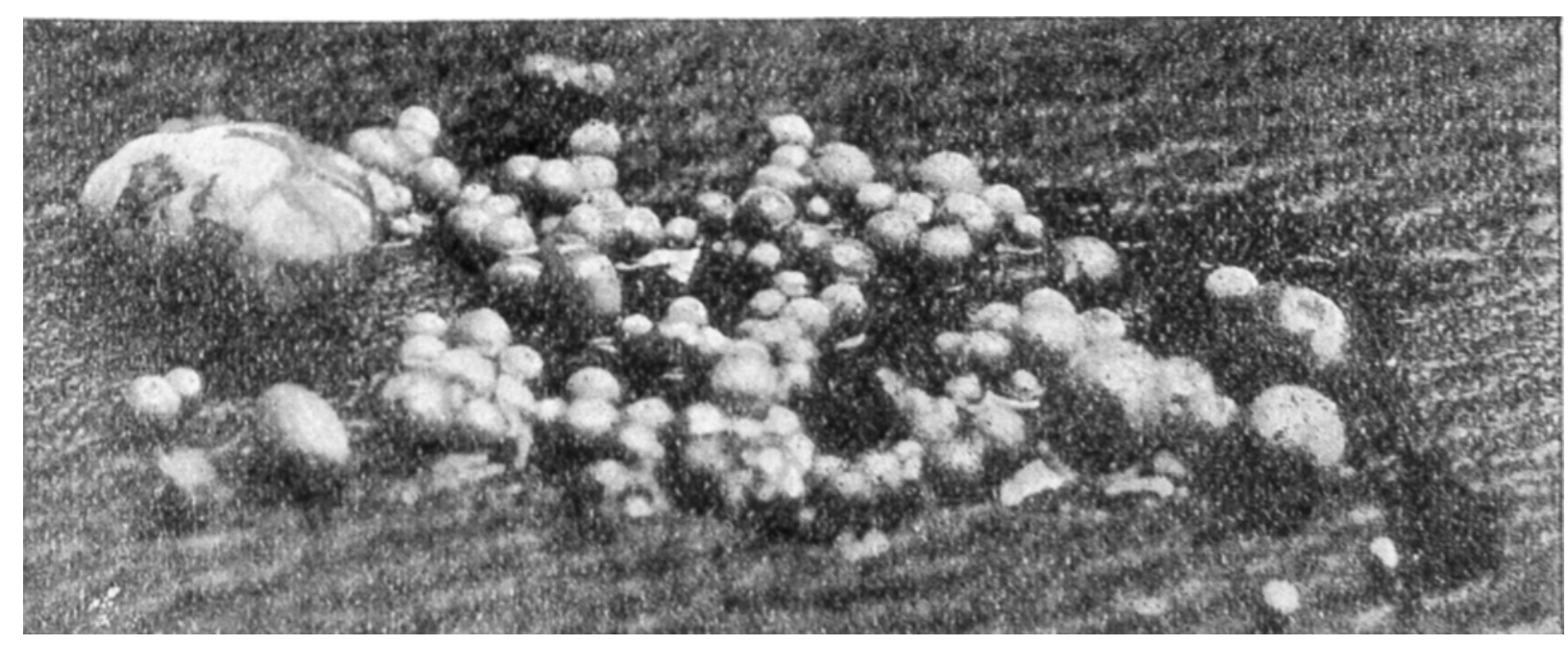

Specimen No. 4.

numerous, varying in size from a grain of snipe shot to swan shot, and one is as large as a bean. The received opinion is that these calculi develop primarily in the 
glandular crypts of the prostate, and that their presence in one pocket is due to an amalgamation of crypts. If this is so, the fact that the pocket was opened into while my finger was working its way through the surgical capsule points very clearly to the origin of that envelope. In the growth removed you see, open it where you may, there is no sign whatever of the existence of such bodies.

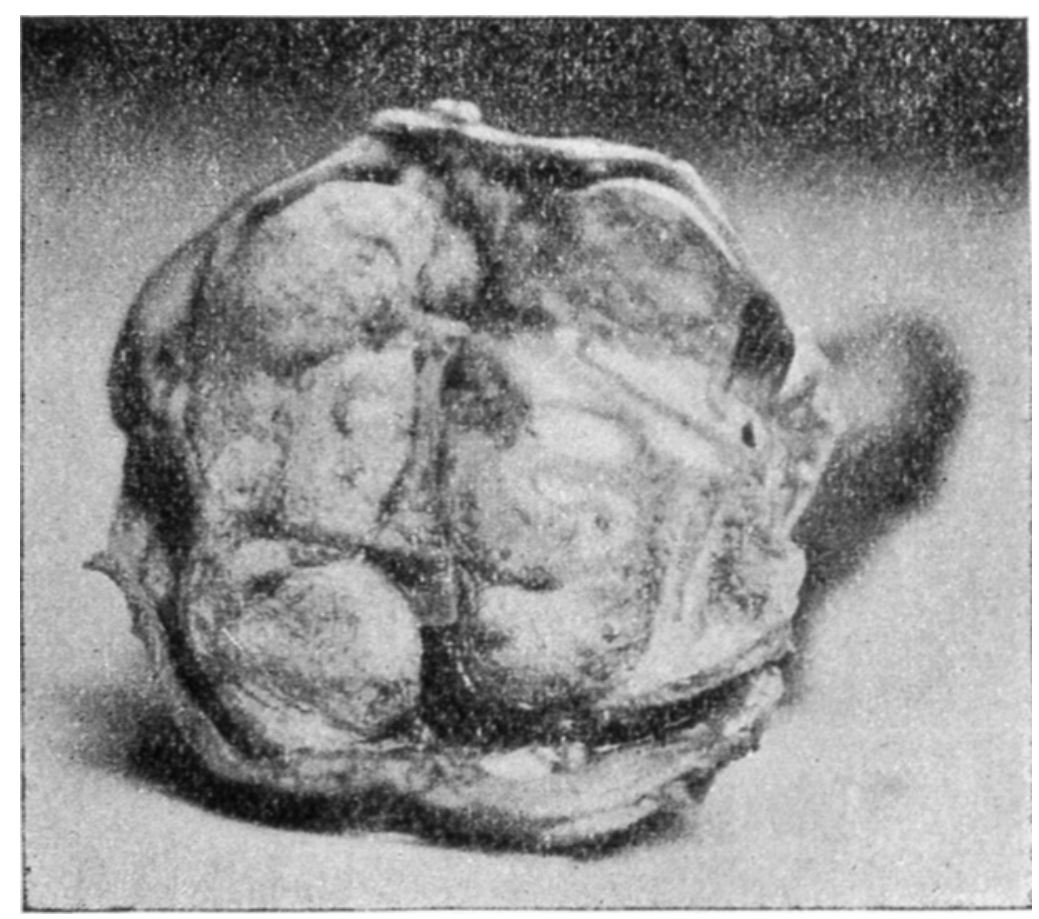

Specimen No. 5.

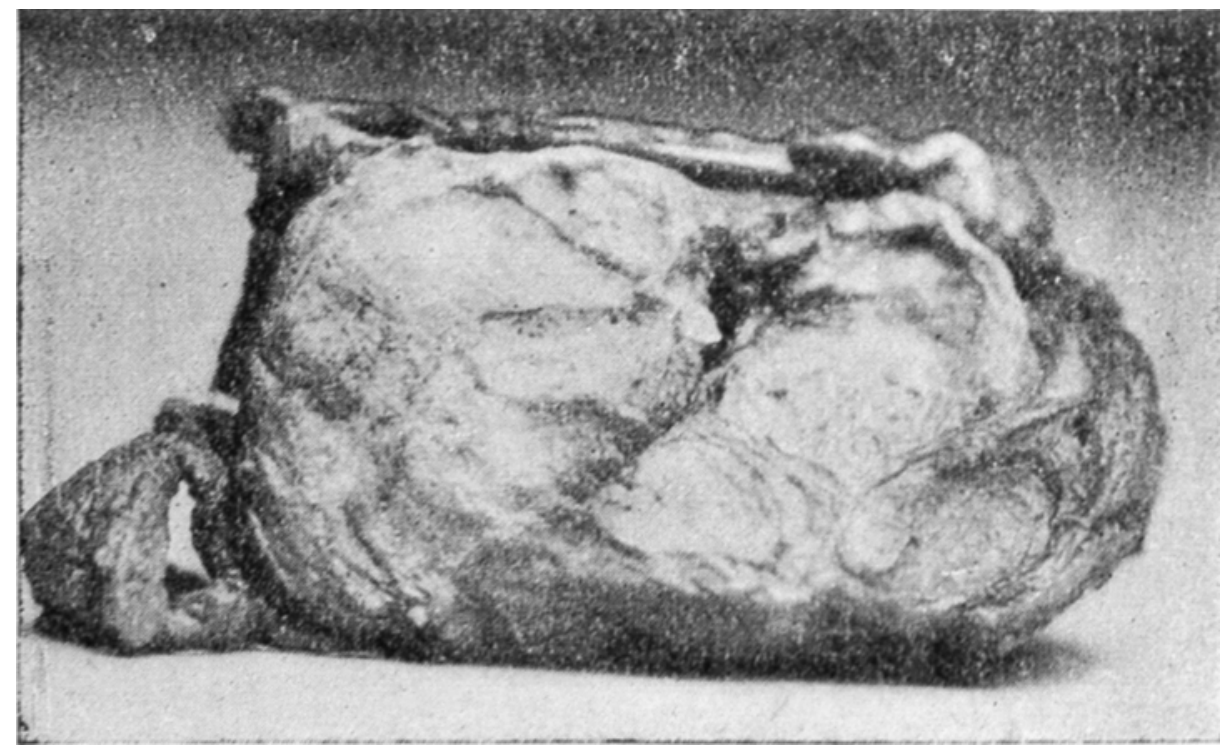

Specimen No. 6.

Specimens Nos. 5 and 6 show adenomatous masses embedded as it were in a fibrous capsule. But the sections of this capsule which Dr. Dargan has made for me 
and placed under the microscopes before us plainly prove that its structure is not fibrous, but composed of fibromuscular and prostatic tissue. These two specimens also show how separable are the masses from this envelope if you cut fully through it; and would incline one to try and enucleate these masses through lateral incisions carried deeply, leaving the capsule and urethra entire. A study of No. 3 specimen, however, shows that by so doing one would often leave behind in the capsule growths that might hereafter bring about a recurrence of urinary obstruction.

It is, therefore, a question of some importance whether the tear one makes in the capsule when proceeding to enucleate is a superficial or deep one.

[For discussion on this paper, see page 344 , post.] 